\title{
The Nature-Nurture Problem Revisited. Some Epistemological Topics in Contemporary Human Sciences
}

\author{
Arnulf Kolstad \\ Nesna University College, Nesna, Norway \\ Email: arnulfk@hinesna.no
}

Received April 5 $5^{\text {th }}, 2013$; revised May $5^{\text {th }}, 2013$; accepted May $12^{\text {th }}, 2013$

\begin{abstract}
Copyright (C) 2013 Arnulf Kolstad. This is an open access article distributed under the Creative Commons Attribution License, which permits unrestricted use, distribution, and reproduction in any medium, provided the original work is properly cited.
\end{abstract}

\begin{abstract}
Humans are from nature biological organisms who become cultural individuals. An essential task for psychology is to clarify the inter-functionality between biology and culture and how higher psychological functions are created when culture "creeps inside" and establishes new human nature in the mind and the brain. Knowledge of the ways in which genes and the environment interact to affect maturation of the brain has changed our understanding of the relationship between nature and nurture, between biology and culture. Hereditary or genetic outfitting unfolds in concert with the environment from the time of conception and during pregnancy. The dynamic interplay between gene action and the environment continues through life. The human mind is a conscious mind developed with cultural tools like language and able to subjugate the non-conscious instinctive and lower psychological "mind" functions. These lower functions are part of the non-volatile mind developing to something else when combined with the higher and cultural mind functions. The psyche is a functional system which acquires a socio-historical character in the transition from the animal organism to the human organism for each individual during the ontogenesis.
\end{abstract}

Keywords: Biology; Culture; Lower Psychological Functions; Higher Psychological Functions; Epigenesis

\section{Introduction}

The relative weight assigned to nature versus nurture in different historical eras has varied. There are historical periods and recent traditions in psychology in which there was no place for any interaction, as if biology and culture were independent entities in terms of human development. The misleading character of such a dichotomous formulation has come to be recognized (Jahoda, 2002). The former sharp distinction between biology and culture is giving way to the recognition of their interrelationship, though its exact nature is still to be discussed and revealed. The inseparability of the two aspects and how we should understand human development as a result of their mutual interdependences, inspired by cultural-historical psychology is one topic considered in this article.

\section{Biology and Culture}

Traditionally, biology and culture have been two distant research areas with different traditions and methods, rooted in different theoretical frames of reference. Culture was often seen as too complex to be studied in the nomological way by "hard" psychological methods (Kornadt, 2002). The term culture refers to human traditions and a stored meaning system analyzed and understood by qualitative methods inspired by hermeneutic and humanistic traditions. In contrast, biology is a "hard", quantitative natural science.

Most professionals today will claim that culture and biology are related to one another. But how this relation or inter-func- tionality happens and what are the characteristics are still controversial and not disclosed in detail in mainstream psychology. Most often the interaction is described as a general principle or as a postulate. Joan G. Miller's describes for instance individuals as simultaneously biological and cultural beings and the two levels as "intertwined and mutually influential" (Miller, 2002: p. 151).

Greenfield (2002) argues that there are different relations between cultural environment and biological nature in human development 1) Culture reinforces biology; 2) Culture appro priates biology; 3) Culture and biology are mutually adapted for survival; 4) Culture selects from biology (the biological substrate provides the foundation for more than one capacity and the environment can reinforce one capacity more than another, for instance individualism more than interdependence); 5) Culture respects biology (Culture has sets of artefacts and practices that respect and stimulate sensitive times of cognitive and neural development); 6) Culture shapes and actualizes biological potential. These relations constitute ways in which culture and biology define and influence each other in development. These relationships make it clear that it is much too simplistic to think of biology on the inside and culture on the outside. The importance of the external culture depends on the internal biological capacity and the culture creep inside and establishes new human "nature" in the mind and the brain (Kolstad, 2012).

The past 30 years have seen unprecedented progress in understanding how the brain develops and, in particular, the changes in both its circuitry and neurochemistry that occur during development (Kolstad, 2013). Knowledge of the ways in 
which genes and the environment interact to affect maturation of the brain has changed our understanding of the relationship between nature and nurture, between biology and culture.

It is essential to understand the interweaving of genetic and environmental influences as they affect both brain and mind. It is time for a new appreciation of the coactivity of nature and nurture in human psychological development. Hereditary or genetic outfitting unfolds in concert with the environment from the time of conception and during pregnancy. The dynamic interplay between gene action and the environment continues through life.

\section{Epigenesis}

Recent work on epigenesis suggests that it is not genes alone, but it is intricate interactions between genetic potentials and environments that ultimately give concrete shapes to human brain, consciousness and behavior (Kitayama \& Park, 2010). Epigenesis is a term in biology that implies development of an organism that unfolds through neuro-chemical mechanisms of cell differentiations. Given its biological origin it should not come as any surprise that epigenesis was long assumed to be under genetic control (Kitayama \& Park 2010). Importantly, however, a number of recent studies (e.g. Suomi, 1999; Gunnar et al., 2001; Meaney \& Szyf, 2005; Lee et al., 2006) have demonstrated how experience (which becomes patterned by culture in human societies) "gets under the skin" during the developmental process to influence the genetic expressions and the structure and function of the brain as well as consciousness and behavior (Kitayama \& Park, 2010). Interactions between genes (and corresponding instinctive and temperamental dispositions) and culture have therefore received intensive research effort in the recent years (Aron et al., 2010; Kim \& Drolet, 2009; Nikolaidis \& Gray, 2010). It would seem likely that various genetic polymorphisms that are unevenly distributed across cultures interact with local ecological environments (e.g. population density) and cultural practices (e.g. parenting and dominant social norms) to yield some of the cultural variations in psychological functions and underlying brain pathways (Chiao and Blizinsky, 2009). Thus, hidden "behind” the cultural variations in mentality and associated brain pathways there might be an important set of mechanisms by which culture/ecology and genetics bi-directionally influence one another over time.

On the basis of recent research and empirical findings in cultural psychology, cognitive psychology and neurosciences, it is good reasons for claiming that higher psychological functions develop from a biological basis and that the mind and brain changes owing to mental and physical activity. The higher psychological functions are humanly constructed when individuals participate in social interaction and communicate by language in a specific culture. The development of higher psychological functions as well as the development of the brain (its function and structure), cannot be explained without focusing on human activity and communication and how culture and biology interact in the process of development.

Undoubtedly there is an inborn capacity to react with specific emotions and instinctive behavior. The first accumulated experiences activate and deactivate the emotion and form the biologically based crystallization points for further motive development. But this is not a uni-linear process based on one genetic factor. It is the product of internal interaction of many neurochemical processes and feedback loops. "The caregiver, in turn, acts accordingly to his/her enduring habits and motives, which are based on biology and experiences, and which again, are shaped by (culture-bound) understanding of the actual situational context” (Kornadt, 2002: p. 208).

There are still disputes on the functioning of the cognitive system and how it is actually installed in the physical nervous system and the rules of operation of the nervous system that are responsible for cognitive and psychological traits, characteristics and function. According to Ira Black at the Department of Neuroscience and Cell Biology, at Robert Wood Johnson Medical School, the environment does not "program" the nervous system. Rather, the environment selects among potentials for characteristics and processes already present in the system thereby eliciting change. The external world triggers the potential for change that is already built into the system (Black, 1991).

\section{The Lower and the Higher Psychological Functions}

The distinction between "lower" or natural psychological functions and "higher" or cultural functions is essential for describing the development of human psychology. The lower functions are biological mechanisms, such as the blind reactions to stimuli that we see in all animals. They do not involve conscious experience. Over time, these lower functions are transformed, and are controlled by higher "cultural” functions (Van der Veer \& Valsiner, 1991, 1994). There are important distinctions between the lower or elementary functions and higher psychological functions. The latter develop from the former and at the same time change the lower ones to something different, absorbing them into new functions by the principle of developing inter-functionality. The elementary functions do not disappear but are changed (and usually reduced in importance) when combined with cultural components in the human mind and brain.

A given psychological function varies qualitatively according to different stages of development. The different processes at different stages of development impact fundamentally different characteristics to function at various periods. Acknowledging qualitative changes in memory, perception, emotion and motivation over phylogenetic and ontogenetic development is central to Lev Vygotsky and Alexander Luria’s thought, representing the cultural-historical approach in psychology. They state that both phylogenetic and ontogenetic development involves primordial characteristics becoming permeated by, subsumed within, and transformed by advanced features. Primordial "lower" characteristics do not retain their original nature and simply coexist, side by side with advanced higher features. It is erroneous to generalize from animals to humans or from infants to adults, because the primitive processes in animals have no ana$\log$ in human adults. Whatever functions they had in animals or infants are completely altered as they become integrated into higher processes. They lose their primitiveness and take on social psychological features. Even psychobiological disturbances at different stages of psychological development will have quite different consequences by virtue of the different related functions in which they are embedded (Luria, 1966).

Higher psychological functions are new formations that develop according to the principle of dialectical inter-functionality, making new psychological functions from the contributing biological and cultural elements. "Perception and memory, 
imagination and thought, emotional experience and voluntary action (cannot) be considered natural functions of nervous tissue or simple properties of mental life. It is obvious that they have a highly complex structure and that this structure has (thereby) acquired new functional attributes peculiar to man" (Luria, 1978: p. 275, in Vygotsky, 1978: p. 43).

The higher psychological functions are also restructuring the brain, stimulating synaptic growth in the plastic brain in many directions creating biological mediations of the brain with consequences for the mind as well. The development of human mind and brain due to cultural influence does not leave out biological factors or disregard biological influences. Quite the contrary; biological phenomena provide the framework for mental phenomena but do not directly determine them. This leaves psychological activity as something to be built up from, rather than reduced to, a biological substratum. To be human means to have surpassed a level of functioning that the biological traits would otherwise dictate (Van der Veer \& van Uzendoorn, 1985). The genetic or instinctive driving forces are overruled by what is acquired during socialization in a particular culture. Cultural psychology is highlighting the role of cultural meanings and practices in completing the psychological functions and in effecting the form of basic psychological processes (Miller, 2002).

The lower functions are biological mechanisms, such as blind reactions to stimuli as we would see in all animals. The elementary or lower functions do not involve conscious experience or cognitive processing of sense data. Over time, these lower functions are transformed and concerted, and they are dominated or controlled by higher "cultural” functions. The (higher) psychological functions are sociocultural and historical in origin. The structure of psychological activity, not just content but also the general forms, change in the course of historical and ontogenetic development. From a phylogenetic point of view "Higher psychological functions (are) the product of the historical development of humanity” (Vygotsky, 1998).

\section{Hegel's Dialectic and Inter-Functionality: A Systemic Approach}

The inter-functionality of lower and higher psychological functions are related in a dialectical manner. With the appearance of psychological functions of a higher order, the lower functions are transformed, becoming elements of a new fusion and being retained in a sublated form. The sublation can be conceived in Hegelian fashion as a dialectical transformation. "Lower" instincts and higher cognitive cerebral parts of the brain and the mind create a new inter-functionality and are the source of development of the "lower" instincts.

The interrelations between elementary functions and higher functions are crucial for an understanding of human development. The analysis of developmental processes allows us to understand the interaction between biological predispositions and environmental information with respect to the initiation of culturally informed developmental pathways (Keller, 2002). The biological heritage and the cultural present are components of the same developmental processes.

The human mind is a conscious mind developed with cultural tools like language and able to subjugate the non-conscious instinctive and lower psychological "mind" functions. These lower functions are part of the non-volatile mind developing to something else when combined with the higher and cultural mind functions. The scientific study of psychology faced the task of overcoming the gap between the natural and the cultural, and "had to transform the ancient conception of the mind in a fundamental way, and to find an alternative to it" (Yaroshevsky, 1989: p. 18). The key concept of psychology was consciousness and this concept was filled with a new content.

Another important aspect of the higher psychological functions is their systemic character. They do not function separately but form an articulate whole. Each of them can therefore be scientifically explained only if the dynamics of its interrelations with the other functions are considered. The study of the psyche must therefore focus on the system of functions as a whole rather than on one separate function tied to a separate center in the brain. The psyche is a functional system that should be grasped in its development, which acquires a sociohistorical character in the transition from the animal organism to the human one and for each individual during the ontogenesis.

To understand for example memory as higher psychological function we have to answer the following questions: What "position" memory has in a whole mind and how the memory structure depends on other components of mind: perception, thinking, planning, motivation, emotion? We also have to clarify how the integrative process takes place in the brain and also how the semiotic mind can "communicate" with the brain. To understand the human mind, including memory, and the relationship between mind and brain, it is necessary to start with a systemic approach rather than from elaborated but context-free details. "Analytic" approaches have to be rejected as relatively unproductive (Toomela, 2008). "The biological heritage and the cultural present are components of the same developmental processes. This view postulates 'transactional relations' between organism and environment, rejecting any simplistic determinism” (Keller, 2002: p. 215).

Memory in humans has to be studied as something mediated by language or signs, and different from non-semiotic, functional systems memory in animals. The architecture of the cognitive system the memory function included, and the brain, changes fundamentally with the inclusion of symbols and language.

\section{Animals and Humans}

There are qualitative differences between the psyche of man and that of (other) animals. The key to man's psychological functions is cultural- and social-genesis, the transformation of culture and social relations, through interiorization, into the individual's psychical acts and with language as a cultural and psychological tool. We do not find this mechanism in animals since they do not have the language tool and are not able to think using a language and therefore develop mentally, in the same way as humans. Language and thought have a particular significance in humans. They constitute each other reciprocally in an internal unity.” Language objectifies, completes, and informs thought just as thinking creates language and produces its meaning...the two processes manifest a unity but not an identity" (Vygotsky, 1987: p. 4). "Speech does not merely serve as the expression of developed thought. Thought is reconstructed as it is transformed into speech. It is not expressed, but completed in the word" (Vygotsky, 1987: p. 251). Thought development is determined by language, i.e., by the linguistic tools of thought and by the sociocultural experience. The child's 
intellectual growth is contingent on his mastering of the social means of thought, that is, language. How it develops is one of the most complex problems in psychology. To solve this puzzle mean to explain a vital psychological function in humans.

Biological instincts and drives determine animal behaviour in natural environments. For humans the biological, elementary and instinctive forces changes to a potentiating, energizing function, they recede in the background and the higher psychological functions govern consciousness and behavior. Humans do not have to obey the instincts or reflexes, but have the option to do what they decide to do after reflecting on the alternatives. No other species have this ability to the same degree. The difference between Homo sapiens and other species in this regard is not only a distinction in degree it is a distinction in principle. To understand development of language in its relation to thought, consciousness and volatile behavior is essential. The relation between thought and speech undergoes many changes. Progress in speech and progress in thought are not parallel. The meanings of words are not a constant. Words undergo evolution especially during childhood but also in adulthood, and an important task is to describe and define the basic steps in that evolution. For instance to uncover the singular way in which the child's "scientific" concepts develop, compared with his/hers spontaneous concepts, and also formulate the laws governing their development means to reveal human development. To demonstrate the specific psychological nature and linguistic function of written speech in its relation to thinking is also an essential task together with clarifying the nature of inner speech and its relation to thought.

Biological determinism or reductionism cannot explain human emotions and behaviour since all higher psychological functions characterizing humans are culturally created. Hormones are for instance involved in all kinds of love, but only as energizing mechanisms, The behavior, thoughts, feelings, and experiences of love is culturally determined and variable and not biologically determined as in animals. Biology has lost its determining function in human behavior, which is only "natural" given the unique cultural environment in which people live. Culture determines the form, content, and conditions of behavior. In contrast, the form, content, and conditions of animal behavior are determined by natural, biochemical elements (Ratner, 2011). Psychology involves and includes natural, biological processes, such as neuronal and hormonal activity, just as it involves breathing air. Just as breathing air is a precondition of psychology which plays no specific determining role in the form, content, mechanisms, and function of psychology, however, so other natural biological processes play no specific determining role either. Their role is analogous to that of breathing. Without breathing, hormones, and the brain, psychological activity would cease; however, with them it is only potentiated, not determined (Ratner, 2011).

Culture determines the form, content, and conditions of behavior for humans. In contrast, the form, content, and conditions of animal behavior are determined by natural, biological elements. Elementary, natural mechanisms are antithetical to cultural-psychological mechanisms and features. The driving forces of biological evolution within the animal world lose their decisive importance as soon as we pass on to the historical development of man. New laws regulating the course of human history which cover the entire process of the material and mental development of human society now take their place (Vygotsky \& Luria, 1930/1993).

\section{Second Nature}

The young child is a pre-cultural biological organism, which becomes transformed by a series of cultural devices such as language, signs and artefacts into a cultural being and thereby acquires the higher psychological functions. In fact the acculturation starts before birth since culture is present at conception and also in mothers' practices, such as her feeding and rest during pregnancy. As Michael Cole has said, the babies are born bathed in amniotic fluid and in culture. At the same time there is no clear dividing line between "natural" and "cultural", especially with regard to the brain. Cultural differences are persistent because our native culture is learned and fastened in our brains. It becomes "second nature" seemingly as "natural" as many of the instincts we were born with. We cannot distinguish our "second nature" from our "original nature" since the neuroplastic brain, once rewired, develops a new nature, every bit as biological as the original (Doidge, 2007), There is no hardwired "nature" in the brain that last a lifetime. The distinction between nature and culture is not easy to draw on the psychological level either, partly because the cultural becomes natural in the brain's structure, and the mind and brain is intermingled.

The tastes our culture creates-in foods, in type of family, in love, in work-often seem "natural" and obvious, even though they may be acquired tastes. Nonverbal communication-how close we stand to other people, the rhythms and volume of our speech, how long we wait before interrupting conversation-all seem "natural" to us, because the behaviours are deeply wired into the brain's "new" nature. When we change cultures, however, we are shocked to learn that these customs, values and attitudes are not natural at all but characterize a particular culture (Doidge, 2007).

\section{Conclusion}

From recent empirical research in cultural psychology and cultural neuroscience we can conclude that all higher psychological phenomena, including perception, cognition, emotion, memory, self-appraisal, motivation, etc. have a cultural character. They are humanly constructed as individuals participate in social interaction and employ cultural/psychological tools. Brains and mind are shaped by experiences in the culture in which humans develop and live. Culture becomes part of each person's nature, stored in their mind and brain. The (higher) psychological functions are sociocultural and historical in origin. The higher-order functions became a possibility since natural evolution made thinking and language appropriation possible, and because we established human cultures which developed higher psychological functions in each individual in whatever culture they were born into (Fiske et al., 1998). When human beings participate in social interactions and employ tools, for instance language and other cultural signs, they develop, construct and create their higher psychological functions, ways of thinking, feeling, remembering, their sensation values, attitudes and perception. These functions are not natural or inborn processes in human adults as they are in animals and human neonates. Culture is a "symbolic medium for human development and participation in this medium is necessary for the emergence of all higher-order psychological processes" (Miller, 2002).

Humans are at the same time biological organisms from na- 
ture, however, the contradictions between the natural and the cultural are the "locomotive" of the history of the child as Vygotsky formulated it. The important task for psychology is to clarify the dialectics between biology and culture in human development and how the higher psychological functions are created by interiorization of culture. There is inter-functionality between the organic maturation and cultural learning which characterizes the merging and the development of a human into a culture. Cultural learning and the acquisition of cultural tools involve a fusion with the processes of organic maturation. The two contributions to development-the natural and the cultural-coincide and penetrate one another and essentially form a single line of sociobiological formation of the man as a cultural human being, developed from a biological being.

\section{REFERENCES}

Aron, A., Ketay, S., Hedden, T., Aron, E. N., Markus, H. R., \& Gabrieli, J. D. E. (2010). Temperament trait of sensory processing sensitivity moderates cultural differences in neural response. Social Cognitive and Affective Neuroscience, 5, 219-226.

http://dx.doi.org/10.1093/scan/nsq028

Black, I. (1991). Information in the Brain: A molecular perspective. Cambridge: The MITPress.

Chiao, J. Y., \& Blizinsky, K. D. (2009). Culture-gene coevolution of individualism-collectivism and the serotonin transporter gene. Proceedings of the Royal Society of Biology, 277, 529-537.

Doidge, N. (2007). The brain that changes itself. NY: Viking Penguin.

Fiske, A. P., Kitayama, S., Markus, H. R., \& Nisbett, R. E. (1998). The cultural matrix of social psychology. In D. T. Gilbert, S. T. Fiske, \& G. Lindzey (Eds.), Handbook of social psychology (pp. 915-981). New York: McGraw-Hill.

Greenfield, P. M. (2002). The mutual definition of culture and biology in development. In H. Keller, Y. H. Poortinga, \& A. Schölmerich (Eds.), Between culture and biology. Perspectives on ontogenetic development (pp. 57-76). Cambridge: Cambridge University Press. http://dx.doi.org/10.1017/CBO9780511489853.004

Gunnar, M. R., Morison, S. J., Chisholm, K., \& Schuder, M. (2001). Salivary cortisol levels in children adopted from romanian orphanages. Developmental Psychopathology, 13, 611-628. http://dx.doi.org/10.1017/S095457940100311X

Jahoda, G. (2002). Culture, biology and development across history. In H. Keller, Y. H. Poortinga, \& A. Schölmerich (Eds.), Between culture and biology. Perspectives on ontogenetic development (pp. 1329). Cambridge: Cambridge University Press. http://dx.doi.org/10.1017/CBO9780511489853.002

Keller, H. (2002). Development as the interface between biology and culture: A conceptualization of early ontogenetic experiences. In $\mathrm{H}$. Keller, Y. H. Poortinga, \& A. Schölmerich (Eds.), Between culture and biology. Perspectives on ontogenetic development (pp. 215-240). Cambridge: Cambridge University Press.

http://dx.doi.org/10.1017/CBO9780511489853

Kim, H., \& Drolet, A. (2009). Express your social self: Cultural differences in choice of brand-name versus generic products. Personality and Social Psychology Bulletin, 35, 1555-1566.

http://dx.doi.org/10.1177/0146167209348641

Kitayama, S., \& Park, J. (2010). Cultural neuroscience of the self: Un- derstanding the social grounding of the brain. SCAN, 5, 111-129.

Kolstad, A. (2012). Inter-functionality between mind, biology and culture: Some epistemological issues concerning human psychologycal development. In M. L. Seidl-de-Moura (Ed.), Human development-Different perspectives (Ch. 2, pp. 19-41). InTech. http://dx.doi.org/10.5772/37595

Kolstad, A. (2013). Epistemology of psychology-A new paradigm: The dialectics of culture and biology. Hauppauge New York: Nova Science Publishers.

Kornadt, H.-J. (2002). Biology, culture and child rearing: The development of social motives. In H. Keller, Y. H. Poortinga, \& A. Schölmerich (Eds.), Between culture and biology. Perspectives on ontogenetic development (pp. 191-211). Cambridge: Cambridge University Press.

Lee, T. I., Jenner, R. G., Boyer, L. A. et al. (2006). Control of developmental regulators by Polycomb in human embryonic stem cells. Cell, 125, 301-313. http://dx.doi.org/10.1016/j.cell.2006.02.043

Luria, A. R. (1966). The human brain and psychological processes. Ney York: Harper \& Row.

Meaney, M. K., \& Syzf, M. (2005). Maternal care as a model for experience-dependent chromatin plasticity? Trends in Neuroscience, 28, 456-462. http://dx.doi.org/10.1016/j.tins.2005.07.006

Miller, J. G. (2002). Integrating cultural, psychological and biological perspectives in understanding child development. In H. Keller, Y. H. Poortinga, \& A. Schölmerich (Eds.), Between culture and biology. Perspectives on ontogenetic development (pp. 215-240). Cambridge: Cambridge University Press. http://dx.doi.org/10.1017/CBO9780511489853.008

Nikolaidis, A., \& Gray, J. R. (2010). ADHD and the DRD4 exon III 7-repeat polymorphism: An international meta-analysis. Social Cognitive and Affective Neuroscience, 5, 188-193. http://dx.doi.org/10.1093/scan/nsp049

Ratner, C. (2011). Macro-cultural psychology. In J. Valsiner (Ed.), Oxford handbook of culture and psychology. Oxford: Oxford University Press.

Suomi, S.J. (1999). Developmental trajectories, early experiences, and community consequences: Lessons from studies with rhesus monkeys. In D. Keating, \& C. Hertzman (Eds.), Developmental health and the wealth of nations (pp. 185-200). New York: Guilford Press.

Toomela, A. (2008). Afferent synthesis and theory of functional systems. Presentation at the Conference on Cultural and Social Psychology at Norwegian University of Science and Technology (NTNU), November 2008, Trondheim.

van der Veer, R., \& Valsiner, J. (1991). Understanding Vygotsky: A quest for synthesis. Cambridge: Blackwell.

van der Veer, R., \& Valsiner, J. (1994). The Vygotsky reader. Cambridge: Blackwell.

van der Veer, R., \& van Uzendoorn, M. H. (1985). Vygotsky’s theory of the higher psychological processes: Some criticisms. Human Development, 28, 1-9. http://dx.doi.org/10.1159/000272931

Vygotsky, L. S. (1978). Mind in society. The development of higher psychological processes. Cambridge: Harvard University Press.

Vygotsky, L. S. (1987). Collected works (Vol. 1). New York: Plenum Press.

Vygotsky, L. S. (1998). Collected works (Vol. 5). New York: Plenum.

Vygotsky, L. S., \& Luria, A. (1930/1993). Studies on the history of behavior. Ape, primitive, and child. Hillsdale, NJ: Erlbaum.

Yaroshevsky, M. (1989). Lev Vygotsky. Moscow: Progress Publisher. 